\title{
Reviving the performative hypothesis?
}

Peter van Elswyk, University of Wisconsin-MilwaukeE

Penultimate draft $\cdot$ Forthcoming in Thought

A traditional problem with the performative hypothesis is that it cannot assign proper truth-conditions to a declarative sentence. This paper shows that the problem is solved by adopting a multidimensional semantics on which sentences have more than just truth-conditions. This is good news for those who want to at least partially revive the hypothesis. The solution also brings into focus a lesson about what issues to consider when drawing the semantics/pragmatics boundary.

\section{The performative hypothesis}

The performative hypothesis or PH holds that every declarative represents the speaker, the addressee, and how the speaker is related to the declarative's truthconditional content (Ross 1970; Schreiber 1972; Sadock 1974). Let us reserve THE PREFACE to name this syntactic representation. Declaratives like (1), which do not overtly display the preface, were analyzed as being syntactically and semantically equivalent to declaratives like (2) that did. The only meaningful difference between (1) and (2) is that the preface is elided in (1).

(1) Robin drank tea.

(2) I predict to you that Robin drank tea.

What PH offered was a grammatical explanation for what a speaker does with a sentence. That (1) is a prediction is not owed to a constellation of extra-semantic facts about conventions, norms, and/or the psychological states of participants. It is owed to the meaning of the covert preface. That covert preface indicates that the speaker is predicting that Robin drank tea to the addressee. If (1) performed another act like an assertion, it would also be because the preface indicated as much.

PH did not initially age well. It faced syntactic and semantic problems alike. And yet a partial resurgence is underway. In syntactic corners, it is increasingly common to theorize that the syntax of a sentence represents some if not all of the components of a speech act (Ernst 2002; Speas and Tenny 2003; Haegeman and Hill 2014; Wiltschko and Heim 2016). To pick one example, Speas and Tenny 
(2003) take there to be a preface that represents the speaker, the addressee, and a body of information that is indexed either to the speaker or the addressee. Note that these three components are not sufficient for individuating some speech acts. Both conjectures and assertions, for instance, involve a speaker, addressee, and body of information. But the three components are still enough to distinguish between some acts. A question, according to Speas and Tenny, indexes the body of information to the addressee whereas acts like assertions or guesses index the body of information to the speaker. So who the body of information is indexed to will at least coarsely settle what is being done with the sentence.

The renewed versions of PH differs in how preface's syntax is understood. On the old view, the preface was a lexical projection hosting a performative verb alongside first and second-person pronouns. The new view regards the preface as a functional projection that does not correspond to any lexical items. Such a difference enables the revived PH to avoid many of the syntactic problems that initially afflicted $\mathrm{PH}$.

However, renewed attention has not been directed to solving PH's semantic problems. This oversight is surprising. Partial versions of PH can also be found in semantic corners. For example, many hypothesize that declaratives host a preface indicating that the speaker is asserting the truth-conditional content (Kratzer and Shimoyama 2002; Chierchia 2006; Alonso-Ovalle and MenéndezBenito 2010; Hacquard 2006, 2010; Meyer 2013, 2014). The motivation for hypothesizing as much is often the same. A linguistic phenomenon is being explained that is easier to account for in an embedded environment than in an unembedded environment. To ease explanation, the unembedded is assimilated to the embedded by positing an assertoric preface. But none tackle the semantic problems of $\mathrm{PH}$.

The most prominent is what I call the TRUTH-CONDITION PROBLEM (Cohen 1964; Lycan and Boër 1980). The problem can be framed in a few ways. Here's my preferred framing. The preface takes wide-scope to make a semantic contribution to a declarative. It can be thought of as a function from a truthconditional content-what I call the PREJACENT- to a performative content. Assuming that the semantic contribution made by the preface is to a sentence's truth-conditions, the truth-conditions of a declarative are determined by the prejacent alone or they are determined by the performative content. Those are the options. But neither delivers the proper truth-conditions. Suppose (2) is true if (1) is. That supposition leads to disaster. We can easily imagine a solitary individual silently drinking tea. In our imagined scenario, (1) is true but (2) is not because no speech act is performed with an addressee. Alternatively, suppose (1) is true if (2) is true. The trouble returns. We can easily imagine a speaker uttering (1) to an addressee with no tea nearby in a world where Robin never has and never will drink tea. In our imagined scenario, (2) is true when (1) is not. 
Regardless of how one understands the syntax of the preface, the truthcondition problem will persist. The representation of the speaker, addressee, and the way the speaker is related to an underlying content still contribute to the meaning of a declarative. To deny as much is to deny a key tenet of contemporary syntax according to which every element is semantically interpreted (Chomsky 1995). Even if we give up the assumption that the preface can only make a semantic contribution by influencing a declarative's truthconditions, what kind of contribution the preface makes remains to be specified if the hypothesis can be revived.

Fortunately, new and old versions of PH alike can straightforwardly solve the truth-condition problem by adopting a multidimensional semantics. Or so I will argue in this paper. This is good news for linguists and philosophers wanting to partially or fully revive PH. It is also instructive. Even if one has no interest in reviving $\mathrm{PH}$, the multidimensional solution to the truth-condition problem enables a new lesson about how to understand the semantics/pragmatics boundary.

\section{Multidimensionality}

A semantic theory is MULTidimensional when it assigns multiple contents to a sentence. I adopt the theory of Gutzmann (2015) on which sentences carry two contents: truth-conditional and use-conditional content. ${ }^{1}$ While truthconditional content can be represented as a set of worlds that is true when the actual world is among them, use-conditional content can be representedfollowing unpublished work by Kaplan (2004)_as a set of contexts that is felicitous when the context of use is an element. Within such a theory, an expression can contribute only to truth-conditions, to use-conditions but not truth-conditions, or to both contents.

Expressions thought to require a multidimensional semantics include slurs, honorifics, evidentials, vocatives, modal particles, and parenthetical verbs (Kaplan 2004; Potts 2004; McCready 2010; Gutzmann 2015; Kirk-Giannini 2019; van Elswyk forthcoming). On a multidimensional approach to slurs, for example, terms like Redneck contribute both to truth-conditions and useconditions. At the level of truth-conditions, redneck contributes information about the socioeconomic status of an individual. But derogatory content is contributed at the level of use-conditions.

A solution to the truth-condition problem readily presents itself when theorizing within a multidimensional semantics. The preface receives a meaning

${ }^{1}$ Nothing hangs on this choice. The solution only requires a multidimensional semantics with compositional interaction between the dimensions. As such, one could treat the preface as contributing a conventional implicature as opposed to use-conditional content (Potts 2004; McCready 2010). 
where it only contributes to use-conditions. The truth-conditions of a sentence are therefore determined by the prejacent. As such, the preface makes zero contribution to a sentence's truth-conditions. But this is not because it does not make a semantic contribution. It makes a contribution to use-conditions by introducing a secondary content that the speaker is presenting the primary content in a particular way to the addressee of the context. The truth-condition problem is solved because the preface is a function to a content in another dimension altogether.

That's the solution in brief. Let's move more slowly and see the solution with the machinery of $\mathcal{L}_{\mathrm{TU}}$, a logic owed to Gutzmann (2015). The semantic value of an expression is three-dimensional in $\mathcal{L}_{\mathrm{TU}}$. There is a dimension for truth-conditional content $(t)$, a dimension for use-conditional content $(u)$, and third dimension that facilitates semantic composition between the previous dimensions $(s)$. We can represent the three-dimensional semantic value as follows.

(3) $\underbrace{t \text {-dimension }}_{t \text {-content }} \bullet \underbrace{s \text {-dimension }}_{u \text {-active content }} \cdot \underbrace{u \text {-dimension }}_{u \text {-saturated content }}$

The $t$-dimension and the $s$-dimension are separated by ' $"$ ' while the $s$-dimension and $u$-dimension are separated by ' $\bullet$ '

On the solution proposed, the preface receives such a three-dimensional meaning. Where $\mathcal{P}$ is the preface, the meaning that avoids the truth-condition problem is (4).

(4) $\llbracket \mathcal{P} \rrbracket^{c}=\lambda p \cdot p \cdot \lambda p .\left\{c \mid \mathcal{R}\left(c_{\mathrm{S}}\right)\left(c_{\mathrm{A}}\right)(p)\right\}$

Consider the $t$-dimension. $\lambda p . p$ is an identity function that passes the prejacent along unadulterated. As a result, no change is made to the truth-conditions. Where the preface makes its contribution is in the next dimension. Within $\mathcal{L}_{\mathrm{TU}}$, ordinary expressions have duplicate content in the $t$-dimension and $s$-dimension (Gutzmann 2015, §4.4). So the same proposition that was passed along in the $t$-dimension composes with $\lambda p .\left\{c \mid \mathcal{R}\left(c_{\mathrm{S}}\right)\left(c_{\mathrm{A}}\right)(p)\right\}$ in the $s$-dimension. Here $\mathcal{R}$ is a triadic relation that indicates the illocutionary manner in which the speaker of the context $\left(c_{\mathrm{S}}\right)$ is presenting a truth-conditional content $(p)$ to the addressee of the context $\left(c_{\mathrm{A}}\right)$. What the $s$-dimension of the preface therefore contains is a function from a truth-conditional content to a use-conditional content. ${ }^{2}$

To illustrate, suppose the speaker and addressee are about to watch footage of Robin from earlier. Before they do, the speaker utters Robin drank tea as a

2 There is nothing in the $u$-dimension of $\mathcal{P}$ because there is not yet a fully saturated useconditional content. Once the preface composes with a truth-conditional content in the $s$ dimension, it will be moved to the $u$-dimension according to use-conditional elimination, a composition rule in $\mathcal{L}_{\mathrm{TU}}$. 
prediction of what they are about to see. According to $\mathrm{PH}$, that sentence hosts a preface indicating that the utterance is a prediction. Implementing PH in a multidimensional semantics would yield an entry like the following for that preface:

(5) $\llbracket \mathcal{P} \rrbracket^{c}=\lambda p \cdot p \cdot \lambda p \cdot\left\{c \mid \operatorname{PREDICT}\left(c_{\mathrm{S}}\right)\left(c_{\mathrm{A}}\right)(p)\right\}$

Treating a proposition as set of worlds, the prejacent in Robin drank tea is \{w Robin drank tea in $w)$ \}. When the prejacent composes with the preface, (6) is produced:

(6) $\{w \mid$ Robin drank tea in $w)\} \bullet\left\{c \mid \operatorname{PREDICT}\left(c_{\mathrm{S}}\right)\left(c_{\mathrm{A}}\right)(\{w \mid\right.$ Robin drank tea in $w)\})\}$

Nothing happens in the $t$-dimension. However, a fully saturated use-conditional content is formed in the $s$-dimension. That secondary content for the sentence Robin drank tea states that the speaker is issuing a prediction to the addressee that Robin drank tea. ${ }^{3}$

With the newer versions of $\mathrm{PH}$ on which the preface is a functional projection, one can hypothesize that the use-conditional meaning is hard-wired into the preface. With the old version, the problem is still solved with a multidimensional semantics albeit with an extra step. The source of the truth-condition problem for PH was analyzing (1) and (2) as being semantically equivalent. If a preface like I predict to you that contributes to truth-conditions, PH runs aground on the obvious fact that (1) and (2) have different truth-conditions. If it contributes to use-conditions, the problem is avoided. But stipulating that $I$ predict to you that contributes only to use-conditions is a non-starter. The verb and first and second-person pronouns ordinarily have truth-conditional meanings.

Once again, a multidimensional semantics helps. Following van Elswyk (forthcoming), we can introduce ' $\otimes$ ', a DIMENSION SHIFTER that lives in the functional projection. It belongs to the family of shunting operators that are standard to multidimensional theories that facilitate compositional interaction between dimensions (McCready 2010; Gutzmann 2015). Two important jobs are performed by $\otimes$ : it erases an expression's truth-conditional content in the

\footnotetext{
${ }^{3}$ A choice-point for PH is elaborating how a sentence hosts a specific performative verb. Above I've schematically represented the verb with $\mathcal{R}$ as a placeholder and replaced it with predict in my illustration. One elaboration is that declaratives are ambiguous. There are then as many disambiguations for each and every declarative as there are possible prefaces. Another option is to interpret $\mathcal{R}$ as a context-sensitive variable as opposed to a placeholder. On this option, the preface would indicate that the speaker is $\mathcal{R}$-ly presenting the truth-conditional content to the addressee but what value $\mathcal{R}$ has would depend on context. This second option is clearly preferable. With it, what a speaker does with a sentence is not entirely determined by the grammar. It would be determined by the grammar in context. As a result, what a speaker does with a sentence would partly be a matter of metasemantics in the sense of Kaplan (1989).
} 
$t$-dimension and introduces unsaturated use-conditional content into the $s$ dimension. In this way, it converts an expression that ordinarily contributes only to truth-conditions to one that contributes only to use-conditions. The operator is detailed below. Where $\mathcal{E}$ is a variable for the preface, $\otimes$ has this semantics.

(7) $\llbracket \otimes \rrbracket^{c}=\lambda \mathcal{E} . T \cdot \lambda \mathcal{E} \cdot \lambda p \cdot\left\{c \mid c_{w} \in \mathcal{E} p\right\}$

Above, $T$ stands for the set of all worlds. So at the the truth-conditional level, $\otimes$ erases an expression's truth-conditional content as a subset of worlds by sending it to the set of all worlds. At the use-conditional level, $\otimes$ forms a use-conditional content stating that the individuals specified are related in the way indicated by the preface to a truth-conditional content. In short, (7) composes with a preface to produce (4).

An example will clarify what $\otimes$ does. A preface on the original version of PH consists of first and second-person subjects and a performative verb like the phrase I predict to you that. We can represent that as (8). It is a function from a truth-conditional content $p$ to another truth-conditional where the speaker predicts $p$ to the addressee.

(8) $\llbracket$ I predict to you that $\rrbracket^{c}=\lambda p \cdot\left\{w \mid \operatorname{PREDICT}\left(c_{\mathrm{S}}\right)\left(c_{\mathrm{A}}\right)(p)\right.$ in $\left.w\right\} \bullet \lambda p \cdot\{w$ $\mid \operatorname{PREDICT}\left(c_{\mathrm{S}}\right)\left(c_{\mathrm{A}}\right)(p)$ in $\left.w\right\}$

As mentioned earlier, $\mathcal{L}_{\mathrm{TU}}$ duplicates what happens in the $t$-dimension and $s$ dimensions for ordinary expressions. When (8) composes with $\otimes$, the dimension shifter, different results are produced across the semantic dimensions.

(9) $T \cdot \lambda p .\left\{c \mid c_{w} \in\left\{w \mid \operatorname{PREDICT}\left(c_{\mathrm{S}}\right)\left(c_{\mathrm{A}}\right)(p)\right.\right.$ in $\left.\left.w\right\}\right\}$

The $t$-dimension erases the content of the preface. In the $s$-dimension, the preface becomes a function from a truth-conditional content $p$ to a use-conditional content. That use-conditional content states that the world of the context $\left(c_{w}\right)$ is an element of the truth-conditional content holding that the speaker asserts $p$ to the addressee. Such a content is just a roundabout version of the use-conditional content in (5).

What we are left with is just one meaning for each constituent in I predict to you that that can be dimension shifted to produce a use-conditional meaning. We can accept that an expression like I predict to you that sometimes contributes to truth-conditions and sometimes contribute to use-conditions without positing lexical ambiguity. ${ }^{4}$ Though there are still syntactic problems with the original $\mathrm{PH}$ that revived versions lack, the ability to introduce an operator like $\otimes$ showcases what can be achieved within a multidimensional semantics.

\footnotetext{
${ }^{4}$ My proposals have commonalities with the view of sentence mood found in Gutzmann (2015, §5) and the view of parenthetical verbs found in van Elswyk (forthcoming). But there are important syntactic and semantic differences. On the current proposal, the use-
} 


\section{Retaining explanatoriness}

PH was introduced to explain a wide variety of data. Does going multidimensional interfere with such explanations? It does not. Space does not permit consideration of every line of data. Still, let's consider speech act adverbs or SA-adverbs like frankly and truthfully for the purpose of illustration. An initial reason for adopting PH that is also a reason for reviving it is that the hypothesis can explain what SA-adverbs modify (Schreiber 1972; Ernst 2002). Compare (10) and (11) and attempt with (11) to interpret frankly as modifying the past tensed verb drank.

(10) Frankly, Robin drank tea.

(11) \# Robin frankly drank tea.

(12) I frankly assert to you that Robin drank tea.

The two differ clearly differ. (10) is intelligible but (11) is not because drinking is not an activity that can be done frankly. Given PH, what explains why (10) alone is intelligible is that frankly modifies the performative verb. Accordingly, (10) can be paraphrased as (12). Asserting, saying, and the like are activities that can be conducted frankly.

Such an explanation of sA-adverbs is unaffected by regarding the preface as contributing to use-conditions. A minor adjustment is required, however. The sA-adverbs must also be understood as contributing to use-conditions as opposed to truth-conditions. A sentence like (10) therefore carries two contents. It carries a truth-conditional content specifying that Robin drank tea, and a useconditional content specifying that the speaker frankly asserted to the addressee that Robin drank tea.

The minor adjustment carries an extra advantage. SA-adverbs do not intuitively contribute to truth-conditions. Consider disagreeing responses to (10) like That's false or No, I don't think so. What these indicate disagreement with is that Robin drank tea. They do not communicate disagreement about the speaker being frank. Going multidimensional enables an explanation of this feature of sA-adverbs. Disagreement targets the truth-conditional content of a sentence. Since sa-adverbs contribute to use-conditions, they cannot be targeted for disagreement.

conditional meaning is not owed to a mood morpheme but the preface, which is a distinct lexical or functional projection depending on the version of $\mathrm{PH}$. That preface does not occupy a parenthetical position either. Semantically, $\mathcal{R}$ can also take as many values as there are speech acts that can be performed by using a declarative. See $f n$. 3 for related discussion. The best grammatical explanation of what speakers do with a sentence may be provided by these other proposals. However, assessing as much is not the aim of the present paper. 


\section{Assertion operators}

So far, I've discussed the multidimensional solution to the truth-condition problem generally. Assertion operators are the most commonly theorized preface. Accordingly, let's give them a closer look. I illustrate with the operator proposed by Meyer $(2013,2014)$. Meyer is compelled to posit an assertion operator in developing a grammatical explanation of implicatures. With grammatical explanations, the generation of implicatures is partially owed to an exhaustification operator or ExH in the logical form of a sentence. In positing an assertion operator or $\mathcal{A}$, Meyer is able to derive a variety of different implicatures. For example, a sentence like (13) generates either an uncertainty or a scalar implicature. An uncertainty implicature indicates that the speaker does not know whether Robin drank all of the tea (i.e. $\neg \mathcal{K}_{\text {ALL }}$ ) whereas a scalar implicature specifies that the speaker does know that Robin did not drink all of the tea (i.e. $\mathcal{K} \neg$ ALL).

(13) Robin drank some of the tea.

The exact details of her proposal do not concern us. What does is that Meyer takes this implicature difference to trace back to the scope of $\mathcal{A}$ and ExH. She adopts the common assumption that assertions require or mandate speaker knowledge in what is asserted. As such, the uncertainty implicature is allegedly conveyed when ExH outscopes $\mathcal{A}$ in logical form, and the scalar implicature is generated when $\mathcal{A}$ outscopes ExH.

But $\mathcal{A}$ is liable to inherit the truth-condition problem. Meyer does not say much about its semantics. But if its semantic contribution is to a sentence's truthconditions, (13) will state that the speaker asserts that Robin drank some of the tea, which, given her knowledge-based understanding of assertion, is tantamount to stating that the speaker knows that Robin drank of some of the tea. And yet, (13) states no such thing.

Going multidimensional prevents the problem from surfacing. If $\mathcal{A}$ contributes to use-conditions, Meyer's proposal won't assign the wrong truthconditions to (13). ${ }^{5}$ The requirement imposed by $\mathcal{A}$ that the speaker knows the truth-conditional content will happen at the level of use-conditions as (14) illustrates.

$$
\text { (14) } \llbracket \mathcal{A} \rrbracket^{c}=\lambda p \cdot p \triangleleft \lambda p \cdot\left\{c \mid \mathcal{K}\left(c_{\mathrm{S}}\right)(p)\right\}
$$

The operator above differs from the schematic proposal in (4) with what is in its $s$-dimension. It is a function from a proposition to a set of contexts in which the

${ }_{5}^{5}$ Given that $\mathcal{A}$ requires speaker knowledge, Meyer's proposal is very similar to parentheticalism, the view that declaratives host a covert know-parenthetical. See van Elswyk (forthcoming, §6) for discussion. 
speaker of the context knows that proposition. For the use-conditional content of a sentence to then be felicitous, (14) requires the speaker to know its truthconditional content.

Importantly, going multidimensional does not interfere with the initial purpose for which $\mathcal{A}$ was theorized. There is nothing about the role played by the scopal interaction between $\mathcal{A}$ and ExH in explaining implicatures that requires that interaction to happen at the level of truth-conditions. Moving that interaction to another semantic dimension, as the multidimensional version of $\mathrm{PH}$ requires, just makes the implicature content use-conditional as opposed to truth-conditional in nature. ${ }^{6}$

I cannot promise that every assertion operator that has been posited can smoothly be plugged into a multidimensional semantics. The devil is in the details. But the preceding discussion provides an apt illustration of how going multidimensional can solve the truth-condition problem for a contemporary version of $\mathrm{PH}$ without interfering with the theoretical purpose for which the hypothesis was revived.

\section{The semantics/pragmatics boundary}

I conclude that the truth-condition problem for PH can be solved by adopting a multidimensional semantics and proposing that the preface contributes to a dimension of a sentence's meaning different from its truth-conditions. What the solution illustrates is that the problem was not ultimately with a grammatical explanation of what a sentence does, but a problem with implementing such an explanation in a unidimensional semantics. This is good news for those who want to at least partially revive $\mathrm{PH}$ with assertion operators and similar posits. Their operators need not inherit the truth-condition problem if its meaning is spread across many dimensions. Accordingly, I recommend they go multidimensional.

There is another lesson to be had, a lesson of broader interest. The boundary between the meaning of a sentence and what a speaker does with that sentence is a classic border dispute between semantics and pragmatics. Philosophers almost without exception take an explanation of what a speaker does with a sentence to be the domain of pragmatics. Thus the need for a theory of speech acts to supplement a theory of grammar by appealing to conventions, norms, and/or the psychological states of conversational participants. But one has to wonder

\footnotetext{
${ }^{6}$ This difference is also not as philosophically important as it may seem. As noted in $f n$. 1 , the choice to use $\mathcal{L}_{\mathrm{TU}}$ is unimportant. Were we working in a logic like that found in McCready (2010), the implicatures would just become conventional implicatures. Even sticking with $\mathcal{L}_{\mathrm{TU}}$, use-conditional content can be converted to truth-conditional content (Kaplan 2004; Gutzmann 2015).
} 
how much this traditional demarcation is owed to philosophers theorizing almost exclusively within a unidimensional semantics. I suspect much of it is, and that is understandable. The truth-condition problem or variants thereof will surface whenever one attempts to turn to the grammar for an explanation of what speakers do with a sentence. But the problem can be put to rest with a multidimensional semantics. Readers uninterested in reviving PH should therefore reconsider how to draw the semantics/pragmatics boundary once a multidimensional theory is in the mix. Maybe more is explained by what is in another semantic dimension instead of what is not in the semantics.

In particular, speech act theorizing commonly individuates acts according to conditions needed for the sincere performance of those acts (Austin 1962; Searle 1969). Assertion is standardly thought to require knowledge or belief, for example. In explaining the source of such conditions, the lesson to learn is that appealing to conventions, norms, and/or the psychological states of conversational participants is not mandatory. At least, the truth-condition problem does not make that appeal mandatory. The lesson of this paper is that the conditions could be semantically encoded as long as they are from another dimension. 


\section{References}

Alonso-Ovalle, Luis and Menéndez-Benito, Paula. 2010. "Modal indefinites." Natural Language Semantics 18:1-31.

Austin, J.L. 1962. How To Do Things With Words. Harvard University Press.

Chierchia, Gennaro. 2006. "Broaden your views. Implicatures of domain widening and the 'logicality' of language." Linguistic Inquiry 37:535-590.

Chomsky, Noam. 1995. The Minimalist Program. MIT Press.

Cohen, Jonathan. 1964. "Do illocutionary forces exist?" Philosophical Quarterly 14:118137.

Ernst, Thomas. 2002. The syntax of adjuncts. Cambridge University Press.

Gutzmann, Daniel. 2015. Use-conditional meaning. Oxford University Press.

Hacquard, Valentine. 2006. Aspects of modality. Ph.D. thesis, Massachusetts Institute of Technology.

-. 2010. "On the event relativity of modal auxiliries." Natural Language Semantics 18:79-114.

Haegeman, Liliane and Hill, Virginia. 2014. "The syntacticization of discourse." In Raffaella Folli, Christina Sevdali, and Robert Truswell (eds.), Syntax and its limits, 370390. Oxford University Press.

Kaplan, David. 1989. "Demonstratives." In J. Almong, J. Perry, and H. Wettstein (eds.), Themes from Kaplan, 481-563. Oxford University Press.

-. 2004. "The meaning of ouch and oops: Explorations in the theory of meaning as use." Howison Lecture at U.C. Berkeley. Transcribed by Elizabeth Coppock.

Kirk-Giannini, Cameron D. 2019. "Slurs are directives." Philosopher's Imprint 19:1-28.

Kratzer, Angelika and Shimoyama, Junko. 2002. "Indeterminate pronouns: The view from Japanese." In Yukio Otsu (ed.), Proceedings of the Third Tokyo Conference on Psycholinguistics. Hituzi Syobo.

Lycan, William and Boër, Steven. 1980. "A performadox in truth-conditional semantics." Linguistics and Philosophy 4:71-100.

McCready, Elin. 2010. "Varieties of Conventional Implicature." Semantics and Pragmatics $3: 1-57$.

Meyer, Marie-Christine. 2013. Ignorance and grammar. Ph.D. thesis, Massachusetts Institute of Technology.

-. 2014. "Deriving Hurford's Constraint." Proceedings of SALT 24:577-596.

Potts, Christopher. 2004. The Logic of Conventional Implicatures. Oxford University Press.

Ross, John. 1970. "On declarative sentences." In Roderick Jacobs and Peter Rosenbaum (eds.), Readings in English transformational grammar, 222-272. Ginn \& Co.

Sadock, Jerrold. 1974. Towards a Linguistic Theory of Speech Acts. Academic Press.

Schreiber, Peter. 1972. "Style Disjuncts and the Performative Analysis." Linguistic Inquiry $3: 321-347$.

Searle, John. 1969. Speech Acts. Cambridge: Cambridge University Press.

Speas, Margaret and Tenny, Carol. 2003. "Configurational properties of point of view roles." In Anna Maria Di Scuillo (ed.), Asymmetry in grammar, 315-344. John Benjamins.

van Elswyk, Peter. forthcoming. "Representing knowledge." The Philosophical Review .

Wiltschko, Martina and Heim, Johannes. 2016. "The syntax of sentence peripheral discourse markers: a neo-performative analysis." In Outside the clause: Form and function of extra-clausal constituents, 305-340. John Benjamins. 